\title{
$(\mathrm{cc}) \mathrm{EY}$
}

\section{GINÁSTICA PARA TODOS \\ NA EXTENSÃO UNIVERSITÁRIA: \\ O EXERCÍCIO DA PRÁTICA DOCENTE}

\begin{tabular}{c} 
GYMNASTICS FOR ALL \\
AT THE UNIVERSITY EXTENSION: \\
THE EXERCISE OF THE TEACHER'S PRACTICE \\
GIMNASIA PARA TODA \\
EN LA EXTENSIÓN DE LA UNIVERSIDAD: \\
EL EJERCICIO DE PRÁCTICA DE LOS PROFESORES \\
\hline
\end{tabular}

\author{
Marilia Teodoro de Leles ${ }^{1}$, \\ Lariza Zanini César Nakatani, ${ }^{1}$, \\ Samanta Garcia de Souzal, \\ Lara Torres Lopes ${ }^{l}$, \\ Othon Viollati Neto ${ }^{1}$, \\ Thiago Sousa Monteiro ${ }^{1}$
}

\begin{abstract}
RESUMO
Este trabalho consiste no registro e reflexão sobre a prática docente do professor de Educação Física tendo como enfoque a formação deste através da atuação como monitor no projeto de extensão "Ginástica Para Todos (GPT) na Infância”, da Universidade Estadual de Goiás/Campus Goiânia ESEFFEGO. A estratégia metodológica utilizada se deu a partir da pesquisa descritiva, englobando os aspectos de descrição, registro, análise e interpretação da amostra pesquisada, a partir de estudo de caso, que possuiu como campo o projeto de extensão citado e sujeitos envolvidos (professoras, monitores e alunos), além de análise bibliográfica e documental. Teve como instrumentos de coleta de dados os planos de aula construídos, observações e anotações pessoais registradas durante o processo, anotações a respeito das intervenções e apresentações realizadas em diário de bordo, questionário aplicado aos alunos ao fim do projeto, registros fotográficos e audiovisuais. Para tal análise, parte-se de uma conceituação da GPT, contextualização do projeto de extensão pesquisado e descrição dos caminhos e percursos metodológicos deste, realizando, por fim, uma reflexão da atuação docente e as influências desta na formação dos monitores enquanto futuros professores e o trabalho da GPT no contexto da extensão universitária, a partir das experiências vivenciadas.
\end{abstract}

PALAVRAS-CHAVE: Ginástica para Todos. Extensão. Formação docente.

\begin{abstract}
This study consists of the recording and reflection on the teaching practice of physical education teacher with focus on formation of these by acting as monitors in the extension project Gymnastics for All (GPT) in Childhood of the State University of Goiás / Campus Goiânia ESEFFEGO. The methodological strategy used was made from the descriptive research from case study, encompassing aspects of description, recording, analysis and interpretation of the studied sample, which owned as field extension project cited and subjects involved (teachers, monitors and students), and bibliographic and documentary analysis. For the data collection it was used instruments lesson plans built, observations and personal notes recorded during the process, notes about the interventions and presentations made in the logbook, questionnaire administered to students at the end of the project, photographic and audiovisual records. For this analysis, part is the concept of GPT,
\end{abstract}

${ }^{1}$ Universidade Estadual de Goiás - UEG, Goiânia, Goiás - Brasil.

Contato: marilialeles@hotmail.com

Submetido em: 02 maio 2016 Aceito em: 15 jul. 2016

\begin{tabular}{|l|l|l|l|l|l|l}
\hline CCConexões & Campinas, SP & v. 14 & n. 3 & p. 23-45 & jul./set. 2016 & ISSN 1983-9030
\end{tabular}


contextualizing researched extension project and description of ways and methodological paths of this, realizing, finally, a reflection of teaching practice and the influences of this in the training of monitors as future teachers and the work of GPT in the context of university extension and from life experiences.

KEYWORDS: Gymnastic For All. Extension. Teacher formation.

\section{RESUMEN}

Este estudio consiste en la grabación y la reflexión sobre la práctica docente del profesor de educación física, con especial atención en la formación de éstos, actuando como monitores en la gimnasia del proyecto de extensión para Todos (GPT) en la Infancia de la Universidad del Estado de Goiás / Goiânia ESEFFEGO Campus. La estrategia metodológica utilizada fue hecha de la investigación descriptiva del estudio de caso, que abarca aspectos de la descripción, registro, análisis e interpretación de la muestra estudiada, que poseía como proyecto de extensión de campo citado y sujetos implicados (profesores, monitores y alumnos), y bibliográfica y análisis documental. Para la recolección de datos se utilizó instrumentos construidos planes de lecciones, observaciones y notas personales registrados durante el proceso, notas sobre las intervenciones y presentaciones realizadas en el cuaderno de bitácora, cuestionario administrado a los estudiantes al final del proyecto, fotográfico y registros audiovisuales. Para este análisis, parte es el concepto de GPT, contextualizando proyecto de extensión investigado y descripción de formas y caminos metodológicos de este, al darse cuenta, por último, una reflexión de la práctica docente y las influencias de este tipo en la formación de los monitores como futuros maestros y el trabajo de GPT en el contexto de la extensión universitaria y de las experiencias de la vida.

PALABRAS CLAVE: Gimnasia Para Todos. Extensión. Formación del profesorado. 


\section{INTRODUÇÃO}

A prática da ginástica se faz necessária por estar vinculada à uma tradição histórica cheia de significados culturais aos seus praticantes, possibilitando que os mesmos deem sentido às suas próprias práticas gímnicas. A ginástica, assim como os demais conteúdos da cultura corporal, visa "aprender a expressão corporal como linguagem". Por meio da ginástica, aquele que a pratica, pode-se apropriar de seu conteúdo dispondo de atividades de caráter lúdico, artístico, ente outras categorias que são construídas pela coletividade, por meio do qual exprime sua subjetividade para e com o todo. ${ }^{1}$

A dimensão subjetiva do corpo, do ser, depende de novas práticas, de novos movimentos que possam libertar cada qual em sua própria medida. ${ }^{2}$ Nesse sentido a Ginástica para Todos (GPT), modalidade gímnica lugar deste estudo, tem em sua própria essência a promoção do "[...] encontro do ser humano consigo, com o outro e com o mundo", 3: 43 além do trabalho com os elementos corporais gímnicos das demais modalidades e a produção de seus próprios textos e contextos. Tal modalidade, foi utilizada neste estudo como lócus do processo de ensino/aprendizagem docente na formação acadêmica de alunos do curso de Licenciatura em Educação Física da Universidade Estadual de Goiás (UEG) - Campus Goiânia ESEFFEGO, por meio do projeto de extensão de Ginástica para Todos denominado "GPT na Infância.

Este estudo teve como objetivo refletir sobre a prática docente do professor de Educação Física, tendo como enfoque o professor em formação, no papel de monitor do projeto de extensão acima mencionado. Como característica metodológica, foi escolhido o processo da pesquisa descritiva, englobando os aspectos de descrição, registro, análise e interpretação com amostra não-probabilística intencional. ${ }^{4} \mathrm{O}$ delineamento da pesquisa se deu por um estudo de caso $^{5-6}$ do projeto de extensão "GPT na Infância" e de suas personagens (professores, monitores e demais alunos do grupo), juntamente com análise bibliográfica e documental. Os instrumentos de coleta de dados utilizados foram: planos de aulas produzidos pelos monitores sob orientação das professoras coordenadoras; observações e anotações pessoais de todo o processo; registros em diário de bordo, dos momentos de aula e das apresentações públicas; questionário aplicado aos alunos do grupo ao fim do projeto; alé de registros fotográficos e audiovisuais para acervo do mesmo. A seguir serão desenvolvidas as categorias de trabalho deste estudo, conceituando a Ginástica para Todos, contextualizando o projeto de extensão "GPT na Infância”, descrevendo seus caminhos e a experiência analisada

\begin{tabular}{|l|l|l|l|l|l|l}
\hline (C) Conexões & Campinas, SP & v. 14 & n. 3 & p. 23-45 & jul./set. 2016 & ISSN 1983-9030
\end{tabular}


neste estudo.

\section{A GINÁSTICA PARA TODOS}

A Ginástica para Todos surgiu inicialmente com o nome de Ginástica Geral (GG), e começou a ser difundida com maior ênfase a partir do reconhecimento da Federação Internacional de Ginástica (FIG) a qual, segundo Souza, ${ }^{7}$ se constitui como uma entidade que possui grande influência na área, em âmbito mundial. Neste trabalho utilizaremos ambos os termos, Ginástica para Todos e Ginástica Geral, devido a algumas publicações utilizarem GG, porém daremos preferência para a primeira (GPT).

O nome Ginástica Geral foi utilizado em um primeiro momento para designar a prática da ginástica em um amplo aspecto, por abranger elementos de todas as modalidades gímnicas reconhecidas pela FIG, porém, desvinculando-a, inicialmente, do princípio da competitividade, ou seja, promovendo a vivência lúdica e técnica das diferentes modalidades gímnicas, perpassando por princípios de inclusão, sociabilidade, afetividade, além das possibilidades de vínculo com outras áreas artísticas, como a dança, as artes cênicas e circenses, culminando em produções corporais alegres e espontâneas possibilitando contextualizar as mais diversas temáticas culturais, sociais, dentre outras que se queira realizar, sem perder a essência e elementos próprios da ginástica. "O termo Ginástica Geral passa, então, a ser utilizado para marcar a diferença entre a ginástica 'em geral', 'em suas bases', não competitiva, e a ginástica competitiva, esportivizada." ${ }^{\prime: 41}$

No final da década de XX, surge oficialmente o Comitê Técnico de Ginástica para Todos em um congresso da FIG, nos Estados Unidos da América. A inicialização desse Comitê propiciou uma ampliação das possibilidades de desenvolvimento da GPT, provocando uma difusão dessa modalidade nas diversas Federações e Confederações vinculadas à FIG, incluso a Confederação Brasileira de Ginástica (CBG), na década de $1980 .{ }^{8}$

A Ginástica para Todos possui como característica a ludicidade, permitindo a utilização de aparelhos oficiais e não oficiais, possibilitando ser trabalhada em espaços educacionais, formais e informais, sendo muitas vezes vinculada ao lazer. Porém, achamos importante ressaltar que não se deve perder de vista os elementos técnicos, pois em concordância com Abib, ${ }^{9}$ embora a técnica não deva ser o único objetivo dentro de uma concepção crítica de

\begin{tabular}{l|c|c|c|c|c|c}
\hline (C) Conexões & Campinas, SP & v. 14 & n. 3 & p. 23-45 & jul./set. 2016 & ISSN 1983-9030
\end{tabular}


Educação Física, é importante que o trabalho com a mesma propicie a base motora necessária para que seus praticantes tenham condições de realizar a técnica de maneira eficaz, e segundo Ayoub $^{8}$ a GPT pode promover o desenvolvimento do repertório motor, além de proporcionar interações sociais e afetivas, a partir do incentivo da prática de uma atividade física.

A GG foi inúmeras vezes apontada [...] como uma ginástica para todos, acessível a todas as pessoas, aberta para a participação; como uma ginástica de grupo, com grupo; como uma ginástica simples, sem restrições e regras e que, portanto, cria espaço para a diversidade e para a criatividade; e, em especial, como uma ginástica do prazer, da felicidade e do divertimento. ${ }^{8: 48}$

Podemos dizer que a GPT gera uma oportunidade de vivência de uma prática que se apresenta, muitas vezes, seletiva, excludente e para poucos. Nessa modalidade o respeito à individualidade e particularidades de cada sujeito envolvido se encontram sempre presentes, possibilitando a participação irrestrita de pessoas, em qualquer idade, sem habilidades gímnicas prévias, sem discriminação de gênero e/ou delineamento de estereótipos físico/anatômicos.

Apesar das características marcantes de inclusão e demonstração gímnica que a GPT possui, o Manual de Ginástica para Todos da FIG $^{10}$ aponta a possibilidade de se vivenciar a modalidade em eventos competitivos reconhecidos pela mesma, como o World Gyn For Life Challenge, realizado pela primeira vez em Dornbirn/Áustria no ano de 2009, evento criado pelo Comitê Técnico da FIG, com o intuito de avaliar as performances de grupo, ${ }^{11}$ o qual tem sua terceira edição prevista para acontecer em 2017 em Vestfold/Noruega.

Fernandes e Ehrenberg ${ }^{12}$ apontam que em 2006 a Confederação Brasileira de Ginástica (CBG) apresentava como principais objetivos da GPT: oportunizar o maior número de indivíduos praticantes de atividades físicas baseadas em atividades gímnicas, proporcionando a auto superação, respeitando as singularidades e coletividades, valorizando o intercâmbio sociocultural; favorecendo elos de interação entre as várias áreas expressivas e artísticas com a ginástica, além de promover o bem-estar.

De acordo com Santos, ${ }^{13}$ é necessário que se compreenda a GPT como uma forma expressiva da ginástica, em busca de uma "liberdade" gestual, corporal e criativa dessa modalidade, o que faz com que se torne um equívoco compreendê-la como uma simples composição coreográfica, reduzindo-a a um produto a ser apresentado em festivais e mostras. A Ginástica 
para Todos deve ser trabalhada e entendida como um todo, como um processo e trabalho contínuo, capaz de produzir transformações, além de uma formação, daqueles que a praticam, tanto professores, quanto alunos.

Desta forma, os sujeitos envolvidos neste trabalho compreendem a Ginástica para Todos como uma possibilidade de vivência das diversas modalidades gímnicas, atentando-se à importância do ensino da técnica sem, no entanto, engessar os movimentos nesta, aproveitando a liberdade de criação que esta modalidade possui em dialogar com diversos temas da cultura corporal e das temáticas do cotidiano, transcendendo a prática da ginástica apenas por reprodução e/ou construção de sequências coreográficas, dando ênfase na ludicidade e na sociabilidade, entendida como uma "[...] relação de reciprocidade dos indivíduos entre si (vida em comunidade), relação esta que gera a socialização dos mesmos em caráter de humanização."14: 21 Reciprocidade que constrói e instrui os sujeitos, conectando-os uns aos outros, independente das categorias em que se enquadram.

\section{O PROJETO DE GINÁSTICA PARA TODOS NA INFÂNCIA}

O projeto "Ginástica Para Todos na Infância", consiste em um projeto de extensão da Universidade Estadual de Goiás (UEG), que se realizou no Campus de Goiânia ESEFFEGO. Tal projeto foi um desdobramento da iniciativa de um grupo em difundir e democratizar o acesso à ginástica, dentro da perspectiva da GPT, apresentada anteriormente. A materialização de tal iniciativa se deu a partir do grupo de Ginástica para Todos - Cignus, coordenado pela professora Michele Oliveira, e que contou durante este período com a parceria de um grupo de professoras da mesma instituição, dentre elas Marilia Leles e Lariza Nakatami, professoras coordenadora e colaboradora, respectivamente, do projeto de extensão em foco.

O grupo Cignus iniciou suas práticas por meio da modalidade gímnica Ginástica para Todos em 2010, sendo composto por alunos e professores da Universidade, além de pessoas da comunidade, estendendo suas práticas para outras modalidades gímnicas e da cultura corporal; respeitando as limitações, particularidades de cada indivíduo membro, valorizando o trabalho coletivo e as habilidades presentes nessa diversidade, tendo como premissa de trabalho os elementos que caracterizam a modalidade GPT, concordando com Marcassa: ${ }^{15:} 171$ 
Fundamentando-se nestes princípios, temos defendido a proposta da Ginástica Geral [Ginástica Para Todos] como aquela capaz de garantir a identidade da ginástica, mantendo seu conteúdo e forma, mas transcendendo aos aspectos meramente técnicos que predominam nas concepções mais tradicionais. Tal proposta amplia o universo dos exercícios e atividades ginásticas para uma compreensão de que o movimento gímnico é também expressivo, e de que a expressão é uma possibilidade, não só de comunicação interna, referente ao conhecimento e à percepção que os sujeitos têm das suas próprias qualidades corporais, mas também de uma comunicação e contato entre as pessoas que partilham ou não do mesmo meio social ou de uma mesma sociedade e cultura.

Após algum tempo da constituição do grupo ginástico Cignus, as professoras envolvidas sentiram a necessidade de abranger tais ações, a partir de projetos de extensão que atendessem ao público infantil, levando às pessoas desse grupo a possibilidade de vivenciarem a GPT e seus benefícios. Foi dado do desafio!

Em 2014 o projeto "Ginástica para Todos na Infância foi iniciado, com o intuito de oferecer às crianças da comunidade local, com idade entre 8 a 14 anos, a oportunidade de vivenciar, praticar e aprender um dos elementos da cultura corporal humana: a Ginástica. Além dessa possibilidade por parte das crianças praticantes, o projeto vislumbrou a oportunidade de acadêmicos de outros projetos e grupos envolvidos com esta área de conhecimento, como o Cignus - Grupo de Ginástica para Todos e o mais recente grupo de ginástica da UEG, GEPEGYM - Grupo de Estudos, Pesquisas e Extensão em Ginásticas vivenciaram a prática docente dessa modalidade, além dos estudos realizados acerca da ginástica e da infância, envolvendo produção acadêmica e científica, planejamento e organização das aulas por parte dos mesmos, sob orientação das professoras coordenadora e colaboradora deste projeto.

Compreendemos a criança dentro de uma concepção apoiada no enfoque Histórico-Cultural. Segundo Souza, ${ }^{16: 134}$

A concepção de criança neste enfoque se liga à prática pedagógica, em vista de que, nesta vertente, a aprendizagem é um processo essencial na apropriação das qualidades humanas, pois é a impulsionadora do desenvolvimento.

A Ginástica para Todos situa-se, então, como uma possibilidade de experiência motora para a formação desses sujeitos, não se restringindo apenas ao aspecto motor, podendo auxiliar também no desenvolvimento afetivo, cognitivo e social e até mesmo cultural das crianças, devido às suas características já citadas anteriormente, considerando ainda que, segundo a

\begin{tabular}{|l|l|l|l|l|l|l}
\hline (C) Conexões & Campinas, SP & v. 14 & n. 3 & p. 23-45 & jul./set. 2016 & ISSN 1983-9030
\end{tabular}


FIG: ${ }^{17}$

A ginástica pode ser universal ou altamente especializada. O que oferece algo para satisfazer a todos e a cada um. Se pensarmos que a ginástica como uma pirâmide, a promoção de fundamentos amplos e resistentes por meio de um programa de Ginástica Para Todos se constitui como a base da FIG (Tradução nossa). ${ }^{\mathrm{i}}$

Aos participantes (crianças da comunidade local), o projeto tem como objetivo compreender a essência da proposta da GPT e, a partir da vivência corporal: buscar resultados significativos, no que diz respeito às atitudes perante os colegas; experimentar novas possibilidades de movimentos com materiais alternativos; vivenciar práticas pedagógicas coletivas e participar dos processos de montagem coreográfica. Por parte dos professores e acadêmicos/monitores envolvidos, o projeto vislumbrou: compreender, de forma mais ampla, esta modalidade, materializar o trabalho proposto pela GPT e divulgar, por meio de relatos, artigos e participações em eventos de ginástica, as experiências vividas no mesmo.

Em sua última edição (2015/2) o projeto contou com a participação de 10 crianças, sob a coordenação da professora Marilia Leles, com a colaboração da professora Lariza Nakatani e apoio dos acadêmicos/monitores do curso de Educação Física: Othon Violatti Neto e Lara Lopes, os quais foram de extrema importância para a efetivação do mesmo.

\section{A EXTENSÃO E A FORMAÇÃO DOCENTE - PERCURSOS E CAMINHOS PERCORRIDOS}

Durante as motivações e justificativas pelas quais conduzimos o projeto "GPT na Infância", destacamos alguns dos objetivos das ações de extensão universitária da Universidade Estadual de Goiás que vão de encontro com nossa prática: tornar acessível a comunidade os conhecimentos produzidos e/ou sistematizados pelas Instituições de Ensino Superior (IES); instrumentalizar o processo dialético de teoria/prática em uma visão interdisciplinar, buscando uma consistência teórica e operacional; priorizar a indissociabilidade entre ensinopesquisa-extensão. ${ }^{18}$

Como já foi ressaltado anteriormente, este projeto surgiu da necessidade da democratização do acesso à ginástica para o público infantil, o que vai de encontro com o primeiro objetivo de ações extensionistas destacado acima - tornar acessível à comunidade os conhecimentos

n. 3


produzidos elou sistematizados pelas IES - e também com sa justificativas e conceituações realizadas nos subtítulos anteriores, reforçando assim a necessidade de se trabalhar com a ginástica, em específico a GPT, proporcionando vivências gímnicas que, por diversos fatores, são de difícil alcance para a população em geral.

O segundo objetivo apontado - instrumentalizar o processo dialético de teoria/prática em uma visão interdisciplinar, buscando uma consistência teórica e operacional - converge com um dos objetivos do projeto, também já relacionado, que foi proporcionar, aos acadêmicos da instituição, a oportunidade de vivência/formação docente, para além da teoria. Um dos prérequisitos para se candidatar como monitor do projeto foi ter cursado as duas disciplinas de ginástica da grade curricular do curso de Licenciatura em Educação Física - Ginástica I e Ginástica II, para que tivessem os conhecimentos mínimos das modalidades gímnicas, além da compreensão teórico formal dos conteúdos e de estruturação de planos de aula em ginástica.

Reconhecemos o valor da extensão universitária como lugar de formação docente, espaço de aprendizagens práticas, de culminância com o que se tem aprendido em sala de aula e também como lócus de pesquisa, a fim de compreender, analisar e dar publicidade ao que vem sendo produzido nas IES, portanto a importância do terceiro objetivo elencado acima priorizar a indissociabilidade entre ensino-pesquisa-extensão - vinculando as ações de extensão também com projetos de pesquisa e grupos de estudos, estabelecendo uma retroalimentação tanto para o ensino, quanto para a extensão, além de gerar novas demandas de pesquisa.

Ater-nos-emos, entretanto, em refletir sobre o processo de formação docente proporcionado neste projeto de extensão, visando o papel do monitor/professor em formação e os caminhos percorridos durante o percurso de vigência do projeto em questão, na importância da instrumentalização teórico/prática. Concebendo um dos saberes indispensáveis que Freire ${ }^{19: 12}$ aponta em que o professor em formação deva assumir-se como "[...] sujeito também da produção do saber, se convença definitivamente de que ensinar não é transferir conhecimento, mas criar possibilidades para a sua produção ou a sua construção"

Entendemos como de suma importância, também para a formação docente, a necessidade de

\begin{tabular}{|l|l|l|l|l|l|l}
\hline (C) Conexões & Campinas, SP & v. 14 & n. 3 & p. 23-45 & jul./set. 2016 & ISSN 1983-9030
\end{tabular}


se trabalhar, para além do conhecimento teórico prático, com envolvimento emocional, na superação de limites, na motivação e liberdade da aprendizagem do novo dentro do grupo, entre aluno-aluno e monitor/professor-aluno. Envolvimento que é de suma importância, devido à confiança/segurança que se deve ter para a aprendizagem de novos movimentos que, em muitos casos, exigem auxílio do professor/monitor e/ou de um aluno mais experiente, pois “O que importa, na formação docente, não é a repetição mecânica do gesto, este ou aquele, mas a compreensão do valor dos sentimentos, das emoções, do desejo, da insegurança a ser superada pela segurança, do medo que, ao ser 'educado', vai gerando coragem". ${ }^{19: 15} \mathrm{Ou}$ seja, a superação da insegurança, tanto relacionada ao aluno do projeto que é desafiado pelo monitor/acadêmico à executar determinado movimento, quanto para o monitor/acadêmico que se encontra no desafio do "ser professor", do conhecimento teórico/prático colocado em "xeque".

Cesar $^{14}$ identifica cinco categorias em que se subdividem o papel do monitor/professor, as quais se referem aos aspectos: metodológicos; pedagógicos; sociais; atributos (características); e à rigidez. Dentre elas destacam-se os papéis pedagógicos e sociais que o monitor/professor deve possuir, papéis que por vezes se fundem com o trato pedagógicosocial destinado aos alunos, em que o monitor/professor torna-se

“[...] responsável pela promoção destes espaços de sociabilidade [...] de forma a cultivar a liberdade, em um ambiente lúdico e respeitador para que os integrantes sintam-se incentivados e livres, com ética, em expressaremse, em humanizarem-se [...]"14:46

A formação docente deve caminhar em direção à liberdade, ao respeito às individualidades e diversidades, visar a autonomia, gerar espaços de socialização, de (re) formação, de reciprocidade, atendendo às peculiaridades dos sujeitos envolvidos. Sem deixar de lado o conhecimento teórico/prático e saber técnico, planejando suas intervenções com todos esses princípios e valores envolvidos. Neste sentido, consideramos o planejamento como uma ação necessária e imprescindível no processo de ensino-aprendizagem e formação docente por meio do qual a realização e concretude de nosso projeto se deu a partir da perspectiva de Vasconcellos:20: 63

O planejamento enquanto construção-transformação de representações é uma mediação teórica metodológica para ação, que em função de tal mediação passa a ser consciente e intencional. Tem por finalidade procurar fazer algo vir à tona, fazer acontecer, concretizar, e para isto é necessário estabelecer as condições objetivas e subjetivas prevendo o desenvolvimento da ação no tempo. 
Desta forma o projeto foi organizado em dois momentos. $\mathrm{O}$ primeiro momento constituído de reuniões semanais para planejamento e estudos entre professores e monitores/acadêmicos envolvidos. E o segundo contemplando o público infantil a ser atendido, com aulas para as crianças do projeto, as quais aconteceram no período vespertino, às quartas e sextas feiras entre $14 \mathrm{~h}$ 50min e $16 \mathrm{~h}$ 50min.

Para realização das aulas do projeto, a princípio, foi construído um cronograma de atividades, em que constavam os principais elementos/conteúdos a serem trabalhados em cada período do semestre. Foram trabalhados conteúdos, tais comol; movimentos gímnicos básicos de solo - rolamentos, inversões, equilíbrios, flexibilidade, saltos ginásticos, giros, elementos pré-acrobáticos; figuras de ginástica acrobática - duos, trios e pirâmides estáticas; construção de materiais alternativos - fita-nãooficial da ginástica rítmica; jogos de cooperação, entre outros. O Quadro 1, demonstra a distribuição das atividades de forma cronológica, tendo como base as atividades programadas para o segundo semestre de 2015.

Quadro 1 - Cronograma referente à edição 2015/2 do Projeto GPT na Infância

\begin{tabular}{|c|c|}
\hline PERÍODO & PROGRAMAÇÃO/CONTEÚDO PROGRAMÁTICO \\
\hline Agosto & 4 intervenções \\
\hline $1^{\text {a }}$ Quinzena & - Divulgação do projeto. \\
\hline $1^{\mathrm{a}}$ e $2^{\mathrm{a}}$ intervenções & $\begin{array}{l}\text { Início das atividades com as crianças } \\
\text { - Retomada dos elementos ginásticos trabalhados no semestre 2015/1: rolamentos, } \\
\text { estrela, parada de dois e de três. }\end{array}$ \\
\hline $3^{\mathrm{a}}$ e $4^{\mathrm{a}}$ intervenções & - Jogos que estimulem o trabalho coletivo, cooperação e confiança. \\
\hline Setembro & 9 intervenções \\
\hline $5^{\mathrm{a}}$ à $13^{\mathrm{a}}$ intervenção & $\begin{array}{l}\text { - Trabalho com os elementos ginásticos: Giros, Saltos, Equilíbrios, Flexibilidade } \\
\text { e Ritmos; } \\
\text { - Elementos acrobáticos: Rolamentos, Paradas (de dois e três apoios), Ponte; } \\
\text { - Fundamentos técnicos para a montagem de figuras acrobáticas em duplas e trios; } \\
\text { - Jogos estimulando o trabalho coletivo, cooperação e confiança; } \\
\text { - Composição coreográfica e construção de materiais alternativos. }\end{array}$ \\
\hline Outubro & 6 Intervenções \\
\hline $14^{\mathrm{a}}$ à $19^{\mathrm{a}}$ intervenção & $\begin{array}{l}\text { - Jogos estimulando o trabalho coletivo, cooperação e confiança; } \\
\text { - Trabalho com os elementos ginásticos; } \\
\text { - Elementos acrobáticos; } \\
\text { - Finalização e limpeza da coreografia que será apresentada no VI Congresso de } \\
\text { GPT e Dança do Centro-Oeste e participação no mesmo. }\end{array}$ \\
\hline $\begin{array}{l}23 \text { e } 24 / 10 / 2015 \\
\text { Novembro }\end{array}$ & $\begin{array}{l}\text { VI Congresso de Ginástica Para Todos e Dança do Centro Oeste } \\
6 \text { Intervenções }\end{array}$ \\
\hline $20^{\mathrm{a}}$ à $24^{\mathrm{a}}$ intervenção. & $\begin{array}{l}\text { - Roda de conversa sobre a participação nas apresentações no VI Congresso de } \\
\text { GPT e Dança do Centro-Oeste (o que acharam, o que sentiram, o que poderia ter } \\
\text { sido diferente, quais as dificuldades que tiveram, etc.); } \\
\text { - Retomada dos elementos gímnicos/acrobáticos e jogos. }\end{array}$ \\
\hline $25^{\mathrm{a}}$ intervenção & $\begin{array}{l}\text { - Finalização das atividades; } \\
\text { - Aplicação do questionário final. }\end{array}$ \\
\hline
\end{tabular}


Sendo assim, as aulas, para crianças, foram organizadas pelos monitores/acadêmicos sob orientação das professoras em três grandes momentos, em consonância com a proposta de organização de aulas apresentada por Soares et al.,." 87 porém "Apenas com finalidade explicativa [...] [o que] não implica romper a solução de continuidade delas". Os três momentos, por sua vez, foram subdivididos pedagogicamente em seis.

\section{Primeiro momento:}

1- Diálogo inicial: Momento em que os responsáveis pelas intervenções, monitores/acadêmicos e professoras do projeto, sentavam com as crianças para conversarem a respeito dos conteúdos trabalhados nas aulas anteriores e apresentação dos elementos a serem trabalhados no dia vigente, realizando uma exposição e conceituação dos mesmos;

2- Preparação: Trabalho com jogos ou atividades em grupo, com caráter educativo para iniciar a aprendizagem de algum elemento gímnico de maior complexidade técnica, preocupando-se em aproximar sempre as características estéticas da ginástica, além de jogos e brincadeiras preconizando os conceitos de cooperação, confiança e trabalho em equipe.

\section{Segundo momento:}

3- Momento gímnico/acrobático: Vivência dos elementos próprios da ginástica, organizados para serem ministrados naquele dia ou semana;

4- Intervalo: Momento de socialização entre o grupo (alunos e monitores/professores) com duração de quinze a trinta minutos, para que as crianças se socializassem e pudessem expressar-se livremente, durante o compartilhar de um breve lanche (os monitores/professores do projeto orientavam os pais/responsáveis pelas crianças que enviassem uma fruta ou algum lanche leve para esse momento);

5- Momento de construção: Período para a construção de aparelhos alternativos de manuseio individual ou coletivo, e/ou produção de sequências coreográficas utilizando os conteúdos trabalhados em aulas 
anteriores e do dia vigente. As sequências coreográficas eram, ora orientadas pelos monitores, ora elaboradas pelas próprias crianças, com vistas à apropriação autônoma dos elementos vivenciados e apreendidos durante as aulas.

\section{Terceiro momento:}

6- Apresentação/Diálogo Final: As crianças eram incentivadas a apresentarem o que era realizado durante a aula, fossem os materiais construídos, ou as sequências coreográficas. Novamente reunidos, os responsáveis pelo projeto e as crianças dialogavam sobre a aula executada e as apresentações realizadas, sendo instigadas a se expressarem quanto às dificuldades e facilidades, suas impressões sobre os elementos trabalhados, a identificação desses elementos, exposição de sugestões para modificações que achassem necessárias, entre outras orientações que se fizessem pertinentes para este momento de fechamento.

Procuramos, desta forma, contemplar os indivíduos envolvidos nesse processo em sua completude de acordo com os papeis identificados por Cesar, ${ }^{14}$ proporcionando momentos de apreensão do conteúdo em suas várias dimensões, conceituando o tema, trabalhando seus fundamentos, técnicas, momentos de vivências práticas, diálogos, refletindo atitudes e valores durante a realização das atividades ali e fora dali, procurando sempre contextualizar os conteúdos trabalhados com a realidade vivida e apresentadas pelas crianças do projeto.

\section{A EXPERIÊNCIA}

Fazer parte deste processo proporcionou aos acadêmicos/monitores uma vivência pedagógica altamente rica, pela qual os mesmos tiveram a oportunidade de exercer a docência sob a supervisão das professoras responsáveis, mas com autonomia para planejarem e levar aos alunos novas experiências, levando em consideração as vivências corporais e sociais que os mesmos traziam consigo. Consideramos este projeto de extensão como um laboratório de GPT, pelo qual todos os envolvidos passaram por crescimento e amadurecimento pedagógico, inclusive as próprias crianças, que foram incentivadas, a todo o momento, a se ajudarem, para além dos aspectos de desenvolvimento gímnico. 
Considerando os objetivos deste projeto de extensão, destacamos dentre eles: compreender a essência da proposta da GPT; vivenciar práticas pedagógicas coletivas aumentando a cooperação entre os alunos e monitores/professores; ampliar a compreensão acerca da Ginástica; experimentar novas possibilidades de movimentos e participar dos processos de montagem coreográfica. Partindo destes objetivos, descrevemos e analisamos abaixo a experiência construída, iniciando pelo processo de planejamento das aulas, o trabalho com os conteúdos gímnicos, o uso dos jogos e brincadeiras permeando a aprendizagem das crianças, e culminando com o processo de elaboração coreográfica e a apresentação deste produto final, além da descrição e análise da aplicação de um questionário para os alunos participantes do projeto. Também refletimos sobre os pontos negativos e problemas vivenciados durante a execução do projeto, o olhar dos acadêmicos/monitores enquanto docentes em formação e apontamentos sobre novas possibilidades de continuidade e expansão do trabalho com GPT para o público infantil.

Ao pensarmos um cronograma inicial, o qual foi orientado pelas professoras responsáveis, tínhamos a hipótese, natural, de que tal planejamento pudesse não se efetivar devido a possíveis contingências, além de não sabermos até que ponto os monitores responsáveis pelas intervenções achariam tal planejamento exequível durante as mesmas. Porém, mesmo com imprevistos, o cronograma foi cumprido de forma satisfatória e os monitores, ao final do processo, em nossa reunião final, afirmaram que o cronograma foi um importante e imprescindível instrumento pedagógico, o qual norteou os estudos e práticas do grupo. Tivemos como base para a construção deste instrumento o calendário da instituição à qual o projeto está vinculado. E as escolhas dos conteúdos se deram, primeiramente, através dos elementos bases da ginástica: correr, saltar, girar, trepar, ressaltando as especificidades estéticas desta área; reforçando, também, outros elementos físicos (trabalho de flexibilidade, resistência e conscientização corporal - elementos importantes para a aquisição e realização de movimentos gímnicos mais complexos e acrobáticos); além do trato afetivo, social e de cooperação.

Para alcançar estes elementos, utilizamos do jogo como ferramenta. Segundo Silva, ${ }^{21: 164}$ brincando, a criança tem acesso a uma

[...] construção cultural transmitida e/ou permitida em qualquer contexto social; experimentada autonomamente ou construída na relação com seus pares,

n. 3


influenciados pela estrutura de rede social (família, igreja, associações, escolas...), processos educativos e acesso a bens materiais e culturais.

Ainda concordando com este autor, ressaltamos a importância do lúdico nas atividades relacionadas à criança, compreendendo que o lúdico não se trata apenas de diversão, mas sim de vivenciar tais atividades de forma alegre e com liberdade, atiçando a criatividade e autonomia para a (re) criação de novas formas de movimento.

Durante as intervenções e execução do cronograma, foi possível perceber uma superação da atuação docente dos monitores envolvidos, além de uma superação gímnica por parte dos alunos. Foi perceptível um clima inicial de timidez por ambas as partes, porém, este foi minimizado a cada intervenção e a cada conquista (conquista de movimentos, de confiança e novos elos de amizade).

Com a utilização de jogos, os quais variavam de acordo com o objetivo da aula (jogos que estimulavam saltos, corridas, estratégias para desenvolver a noção espacial e jogos cooperativos), e após a apropriação de alguns elementos gímnicos executados individualmente, as crianças foram estimuladas a executarem movimentos em duplas, trios e grupos maiores, construindo pirâmides e movimentações baseadas na ginástica acrobática. Também pensamos na construção de aparelhos como a "fita alternativa", adaptação do aparelho da Ginástica Rítmica, e construção de sequências coreográficas, sendo parte de cada aula destinada sempre a uma destas construções, instigando as crianças a criarem, autonomamente, sequências com os elementos apreendidos.

A partir do trabalho com os conteúdos gímnicos, adotamos uma sistematização avaliativa por meio das rodas de conversas. Momento de diálogo entre todos os participantes das aulas para a identificação e apresentação dos conteúdos e conversas sobre as atividades trabalhadas, realizadas ao início e final de cada aula. Neste momento as crianças eram instigadas, a partir de perguntas realizadas pelos monitores, a se expressarem quanto às dificuldades apresentadas, facilidades, o que mais gostaram, além de oportunizar a reflexão dos demais momentos vivenciados na aula, identificando os elementos trabalhados na mesma, dentre outras colocações pertinentes e particulares à cada dia. 
O diário de bordo (anotações pessoais) também foi adotado como forma de registrar, ao fim da aula, dados importantes da mesma, como a interação entre os alunos, as dificuldades apresentadas, avanços, observações pontuadas pelas próprias crianças nas rodas de diálogos, entre outros fatores interessantes, com fins de avaliar o próprio processo educativo, organização e condução das aulas dentro dos pressupostos relacionados acima além da elaboração e apresentação de coreografia.

O processo de elaboração coreográfica, que culminou na coreografia apresentada no VI Congresso de GPT e Dança do Centro-Oeste, no Parque Flamboyant, na cidade de GoiâniaGO, em outubro de 2015, proporcionando com que as crianças vivessem a experiência de se apresentarem em espaços abertos e próximos ao público que as prestigiaram. Tal processo também se constituiu como um instrumento avaliativo, porém não foi um momento totalmente desvinculado ou isolado de todo o processo, ao contrário, a produção coreográfica foi se "materializando" a cada aula, a cada apropriação de movimentos por parte dos alunos, a cada sequência criada por eles ao fim das mesmas, a cada nova experiência ( $5^{\circ}$ fase do segundo momento da aula, como exposto no tópico anterior, referente à organização das aulas). Os monitores ficaram à frente da organização e construção deste produto, se colocando como coreógrafos mediadores e colaboradores, pois, se tratou de uma construção coletiva. Estes passaram, pela primeira vez, pela situação de construção de uma coreografia, pensando de maneira efetiva no processo como um todo, assim como as crianças tiveram a primeira experiência de apresentação artística pública, e mesmo com "amadorismo" dos envolvidos (alunos e monitores do projeto), o resultado foi incrível, resultando em um feedback positivo de familiares e professores da instituição envolvida.

O figurino foi escolhido pelos monitores e professoras, considerando a condição financeira de algumas crianças e pensando, também, na reutilização desta em eventos futuros. O resultado foi uma vestimenta básica, porém, confortável para a realização das movimentações que representavam o universo gímnico. O tema da coreografia consistiu na representação da coletividade, diante de um mundo cada vez mais individualista, tema este que é muito bem apontado pela GPT, ponto de culminância para o encontro de uma coletividade dentro de um turbilhão de uma sociedade cada vez mais líquida. ${ }^{22}$ 
Bortoleto e Patrício, ${ }^{23}$ ao analisarem os Festivais Ginásticos, destacam, a partir da visão de especialistas, a importância da participação nesses eventos, considerando que os festivais possibilitam trocas entre seus participantes, sendo que estes possuem características diversas propiciando um convívio integrado, com diferentes faixas etárias, sexo, diversidade estética, etc., momentos que, segundo os autores, se encontram cada vez mais raros em nossa sociedade.

Ainda segundo os especialistas, os festivais ginásticos apresentam-se como uma excelente oportunidade para fomentar:

- O gosto pela apresentação pública daquilo que foi produzido de modo íntimo e no seio de um grupo;

- O respeito pela diversidade/diferenças;

- A solidariedade e a integração;

- A criatividade;

- A ginástica como possibilidade de prática;

- O convívio social. ${ }^{23: 108-109}$

Ao fim do semestre de 2015/2, findando o cronograma de aulas do projeto, foi aplicado um questionário aos alunos, com o intuito de identificar de que forma compreendiam a Ginástica para Todos e o que o projeto havia proporcionado aos mesmos. A análise dos questionários se deu a partir das categorias: conceituação da GPT; elementos ginásticos apreendidos; importância do projeto; e inclusão/cooperação.

Em relação à conceituação da GPT, todos afirmaram se tratar de uma ginástica que permite a participação de todo tipo de pessoa, sendo que duas dentre as respostas vincularam a GPT à uma modalidade não competitiva. Quanto aos elementos ginásticos apreendidos, os movimentos citados nas respostas foram: rodante (rondada); saltos; estrelinhas (rodas); paradas; rolamentos; ponte; equilíbrios; aberturas (espacates); pirâmides e reversão (ponte para frente). Todas as respostas avaliaram positivamente a importância do projeto e a relevância dos professores/monitores neste processo. E sobre a última categoria avaliada, inclusão/exclusão, todos responderam que nunca se sentiram excluídos das atividades e perceberam de forma positiva a cooperação dos colegas e dos trabalhos em grupos, enxergando tal participação cooperativa como possibilidade de novas amizades, apoio mútuo e possibilidade de aprender coisas novas.

Porém, mesmo com tantos resultados positivos e com a execução satisfatória do cronograma, não é verdade constatarmos que não houveram pontos negativos em todo o processo. Enfrentamos durante essa caminhada muitos empecilhos, dentre eles, a estrutura física

\begin{tabular}{l|l|l|l|l|l|l}
\hline (C) Conexões & Campinas, SP & v. 14 & n. 3 & p. 23-45 & jul./set. 2016 & ISSN 1983-9030
\end{tabular}


disposta para a realização das intervenções. Atualmente contamos com um ginásio que possui uma estrutura fragilizada, que resulta, por exemplo, na não execução das aulas no tatame em dias de chuva, pois, o mesmo fica bastante molhado, podendo acarretar em acidentes. Tivemos à disposição durante as intervenções uma trave de equilíbrio, um tatame de lutas com tamanho de $12 \mathrm{~m} \times 12 \mathrm{~m}$, trampolim reuther, arcos (não oficiais), dois colchões pequenos e um banco sueco para a realização das aulas. Porém, por trabalharmos com uma modalidade de ginástica que visa, também, a utilização de materiais alternativos, tal deficiência material pôde ser superada. Embora a relação entre os pais e monitores/professoras do projeto sempre fosse positiva e de confiança, não havia um espaço adequado no ginásio em que as aulas aconteciam para que os mesmos pudessem acompanhar as atividades confortavelmente, o que no começo resultou em uma situação um pouco constrangedora, mas que, com o aumento da confiança dos responsáveis no trabalho proporcionado a seus filhos, estes começaram a deixar as crianças nas aulas, retornando apenas para buscá-los ao final das mesmas.

Outro ponto falho, e que o grupo envolvido já havia detectado e tentou traçar estratégias para minimizá-lo, foi o alcance de um número maior de crianças. Porém a divulgação do projeto não alcançou outros espaços além dos da própria instituição. A partir das experiências que obtivemos, entendemos que é hora de buscar ampliar essa vivência gímnica para um maior número de crianças, e também para os acadêmicos/professores em formação de nossa instituição. Esperamos que o registro feito neste trabalho possa incentivar essa iniciativa para além dos muros do Campus Goiânia ESEFFEGO da Universidade Estadual de Goiás, e que possa ser repetido e aprimorado ainda mais em outros espaços e públicos.

Entendemos, depois desta rica experiência, que é hora de alçarmos voos maiores e, para isso, é necessário construirmos parcerias. Em conjunto, a ginástica pode ser cada vez mais difundida e democratizada. Atualmente o projeto encontra-se em sua quarta edição, com um grupo maior de acadêmicos envolvidos, contando também com a colaboração do Grupo de Estudos, Pesquisas e Extensão em Ginásticas - GEPEGYM, coordenado pelas professoras Samanta Souza e Lariza Nakatani. Em nosso projeto, para um futuro próximo, planejamos estabelecer parcerias com escolas da rede municipal e estadual de Goiânia, alcançando um grupo maior de crianças a quem são, muitas vezes, negadas a possibilidade de uma prática como a que a Ginástica para Todos oferece. 


\section{CONSIDERAÇÕES FINAIS}

A experiência obtida com as vivências e estudos no projeto "GPT na Infância" foi altamente enriquecedora para as professoras, acadêmicos e alunos da comunidade envolvidos. $\mathrm{O}$ processo de elaboração das aulas, dentro de uma proposta maior, considerando a ginástica em seus vários aspectos, proporcionou elos com a dança, oportunizando que os acadêmicos tivessem de construir uma coreografia e levá-la, juntamente com os alunos do projeto, para eventos que têm tomado proporções cada vez maiores no cenário goiano, propiciando aos envolvidos um amadurecimento pedagógico e reflexões mais abrangentes a respeito da modalidade.

Para os acadêmicos envolvidos neste trabalho, como monitores, foi uma experiência pedagógica imprescindível para a formação profissional - “o se tornar/formar professor”. A extensão possui um importante papel neste sentido, o de proporcionar uma formação, a partir da práxis, ou seja, proporcionando momentos para a realização de uma prática fundamentada teoricamente, sob a supervisão e orientação das professoras do curso envolvidas com este projeto, em um momento "real", com relações sócio afetivas reais, construções, desafios e resultados reais.

Em relação aos alunos envolvidos, o crescimento foi proporcional ao crescimento das professoras e acadêmicos, o que foi possível notar a partir das próprias aulas/intervenções, por meio da aquisição de novos movimentos gímnicos por parte destes, dos feedbacks durante as aulas, devido às respostas obtidas nos questionários e, claro, no produto final, a coreografia apresentada. Em todos esses aspectos foi possível notar a superação e emoção envolvida no processo. Construção de elos que não se perderão e vivências que não serão esquecidas.

Tais experiências nos fez acreditar ainda mais no potencial que a Ginástica para Todos possui, reforçando nossa concepção da mesma, acreditando que é possível sim a prática de uma modalidade gímnica a partir da apropriação de elementos próprios da mesma, sem negar a técnica de tais elementos (pois entendemos que é direito de todo indivíduo se apropriar dos elementos construídos social e historicamente pela humanidade, sendo estes livres para, após a vivência de tais construções, utilizarem destes, ou não) dentro de uma prática pedagógica que visa, também, a liberdade expressiva e (re)criação de movimentos, ressaltando a importância da construção de diálogos com as mais diversas áreas artísticas e temas da

\begin{tabular}{l|l|l|l|l|l|l}
\hline (C) Conexões & Campinas, SP & v. 14 & n. 3 & p. 23-45 & jul./set. 2016 & ISSN 1983-9030
\end{tabular}


cultura corporal. Registramos aqui o início de um trabalho. Início porque sabemos que existem, ainda, pontos que podem e devem ser melhorados, como um maior alcance de crianças e ampliação de repertório gímnico trabalhados, por exemplo. Estamos apertando o start para um processo que procuramos ampliar cada vez mais, não apenas quantitativamente, mas, também, qualitativamente. Existe ainda um longo caminho a ser percorrido e que, sinceramente, não estamos preocupados em alcançar o final, queremos, na verdade, crescermos sempre mais, ampliando o acesso à ginástica, proporcionando novas reflexões e vivências gímnicas, construindo novas perspectivas dentro desta modalidade.

\section{NOTAS}

${ }^{\mathrm{i}}$ Gymnastics can be universal, or highly specialised. It offers something to suit each and every one of us. If one thinks of gymnastics as a pyramid for promoting health and well-being, at its base the FIG's Gymnastics for All programme provides broad and sturdy foundations.

\section{REFERÊNCIAS}

${ }^{1}$ SOARES, Carmen Lúcia et al. Metodologia do ensino da educação física. 2. ed. São Paulo: Autores Associados, 2009.

${ }^{2}$ MIRANDA, Danilo Santos de. Identidades e práticas coletivas. In: FÓRUM INTERNACIONAL DE GINÁSTICA GERAL, 4., 2007, Campinas. Anais... Campinas: FEF-UNICAMP, 2007. p. 33-34.

${ }^{3}$ TOLEDO, Eliana de. Ginástica de Grande Área: Algumas abordagens e reflexões de sua manifestação no Brasil. In: FÓRUM INTERNACIONAL DE GINÁSTICA GERAL, 4., 2007, Campinas. Anais... Campinas: FEF-UNICAMP, 2007. p. 38-43.

${ }^{4}$ MARCONI, Marin de Andrade; LAKATOS, Eva Maria. Técnicas de pesquisa. 6. ed. São Paulo: Atlas, 2006.

${ }^{5}$ GIL, Antônio Carlos. Métodos e técnicas de pesquisa social. 5. ed. São Paulo: Atlas, 1999.

${ }^{6} \mathrm{GIL}$, Antônio Carlos. Como elaborar projetos de pesquisa. 4. ed. São Paulo: Atlas, 2006. 
${ }^{7}$ SOUZA, Elizabeth Paoliello Machado de. Ginástica geral: uma área do conhecimento da educação física. 1997. Tese (Doutorado em Educação Física) - Faculdade de Educação Física, Universidade Estadual de Campinas, Campinas, 1997.

${ }^{8}$ AYOUB, Eliana. Ginástica geral e educação física escolar. Campinas Ed. da UNICAMP, 2007.

${ }^{9}$ ABIB, Pedro Rodolpho Jungers. Educação física escolar: uma proposta a partir da síntese entre duas abordagens. Movimento, Porto Alegre, v. 5, n.10, p. 29-34, 1999. Disponível em: <www.seer.ufrgs.br/Movimento/article/viewFile/2455/1120> Acesso em: 12 maio 2016.

${ }^{10}$ FEDERAÇÃO INTERNACIONAL DE GINÁSTICA. Gymnastics for all manual: regulations manual, 2009. Disponível em: <http://www.figgymnastics.com/publicdir/rules/files/gfa/2009\%20GFA\%20manual-e.pdf> Acesso em: 10 jul. 2016.

${ }^{11}$ BEZERRA, Liudmila de Andrade; GENTIL, Raphael do Nascimento; FARIAS, Gelcemar Oliveira. A ginástica para todos na formação inicial: do contexto histórico à produção do conhecimento. Pensar a Prática, Goiânia, v. 18, n.3, 2015, p.739-751, 2015. Disponível em: <http://www.revistas.ufg.br/fef/article/view/32966/19026> Acesso em: 10 jul. 2016.

${ }^{12}$ FERNANDES, Rita de Cássia; EHRENBERG, Mônica Caldas. A ginástica para todos na sua relação com as atividades físicas orientadas para o lazer. EFDeportes.com: revista digital, Buenos Aires, v. 15, n. 166, 2012. Disponível em: <http://www.efdeportes.com/efd166/a-ginastica-para-todos-para-o-lazer.htm> Acesso em: 12 maio 2016.

${ }^{13}$ SANTOS, José Carlos Eustáquio dos. Ginástica geral: elaboração de coreografias, organização de festivais. Jundiaí: Fontoura, 2001.

${ }^{14}$ CESAR, Lariza Zanini. O papel do monitor no processo de sociabilização de jovens e adultos praticante de ginástica geral: um estudo de caso. 2009. Trabalho de Conclusão de 
Curso (Licenciatura em Educação Física) - Faculdade de Educação Física, Universidade Federal de Goiás, Goiânia, 2009.

${ }^{15}$ MARCASSA, Luciana. Metodologia do ensino da ginástica: novos olhares, novas perspectivas. Pensar a Prática, Goiânia, v. 7, n. 2, p. 171-186, 2004. Disponível em: <http://cev.org.br/biblioteca/pensar-pratica-v7-n2-2004/> Acesso em: 14 abr. 2016.

${ }^{16}$ SOUZA, Maria Cecília Braz Ribeiro de. A concepção de criança para o enfoque histórico-cultural. 2007. Tese (Doutorado em Educação) - Faculdade de Filosofia e Ciências, Universidade Estadual Paulista, Marília, 2007.

${ }^{17}$ FEDERAÇÃO INTERNACIONAL DE GINÁSTICA (FIG). About gymnastics for all. Disponível em: < http://www.fig-gymnastics.com/site/page/view?id=236> Acesso em: 13 maio 2016.

${ }^{18}$ GOIÁS. Universidade Estadual de Goiás. Projeto pedagógico do curso de Educação Física. Goiânia: ESEFFEGO, 2016.

${ }^{19}$ FREIRE, Paulo. Pedagogia da autonomia: saberes necessários à prática educativa. São Paulo: Paz e Terra, 1996.

${ }^{20}$ VASCONCELLOS, Celso dos Santos. Planejamento projeto de ensino-aprendizagem e projeto político-pedagógico. 7. ed. São Paulo: Libertad, 2000.

${ }^{21}$ SILVA, Leonardo Toledo. Jogos, brinquedos e brincadeiras: algumas reflexões. Saber Acadêmico, n. 11, p. 163-171, 2011. Disponível em: < https://www.yumpu.com/pt/document/view/12867491/jogos-brinquedos-e-brincadeirasalgumas-reflexoes-uniesp > Acesso em: 14 maio 2016.

${ }^{22}$ BAUMAN, Zygmunt. Modernidade líquida. Rio de Janeiro: Jorge Zahar, 2001.

${ }^{23}$ PATRÍCIO, Tamiris Lima; BORTOLETO, Marco Antônio Coelho. Festivais ginásticos: princípios formativos na visão de especialistas. Conexões: revista da Faculdade de Educação

\begin{tabular}{|l|l|l|l|l|l|l}
\hline (C) Conexões & Campinas, SP & v. 14 & n. 3 & p. 23-45 & jul./set. 2016 & ISSN 1983-9030 \\
\hline
\end{tabular}


Física da UNICAMP. Campinas, v. 13, n. especial, p. 98-114. Disponível em: < http://periodicos.sbu.unicamp.br/ojs/index.php/conexoes/article/view/8637578> Acesso em: 20 abr. 2016 